\title{
Corneal endothelial morphology and anterior segment parameters in children with type 1 diabetes mellitus
}

\author{
Alper Halil Bayat ${ }^{1 \oplus}$, Şeyma Gülcenur Özturan ${ }^{1 \oplus}$, Akın Çakır ${ }^{1 \oplus}$, Selim Bölükbaş1 ${ }^{1 \oplus}$, \\ Burak Erden $^{1 \oplus}$, Diğdem Bezen $^{2 \oplus}$, Mustafa Nuri Elçioğlu $^{1 \oplus}$ \\ Departments of ${ }^{1}$ Ophthalmology and ${ }^{2}$ Pediatric Endocrinology, Okmeydan Research and Traning Hospital, University of Health \\ Sciences, Istanbul, Turkey.
}

\begin{abstract}
Background and objectives. To compare the corneal endothelial morphology and anterior segment parameters in type 1 diabetes mellitus children (T1DM) and healthy controls.

Methods. This cross-sectional prospective study included 56 patients with T1DM and 50 eyes of 50 age-matched controls. Endothelial morphology was analyzed with EM-3000 specular microscopy, and anterior parameters were analyzed with Sirius Scheimpflug topography. Endothelial cell density (ECD), coefficient of variation (CV) of cell area, central corneal thickness (CCT), anterior chamber depth (ACD), iridocorneal angle (ICA), K1 and K2, pupillary diameter (PD), horizontal visible iris diameter (HVID), duration of T1DM, and HbA1c levels were noted.

Results. The mean age of the T1DM group was $14.3 \pm 3.2$ years, compared to $13.2 \pm 3.7$ years in the healthy group $(p=0.140)$. The mean duration of diabetes mellitus was $4.5 \pm 3.5$ years. The mean HbA1c was $9.5 \pm 1.9 \%$ (minimum $6 \%$, maximum 14\%). The mean values of CCT were $556 \pm 30 \mu \mathrm{m}$ and $536 \pm 36 \mu \mathrm{m}$ in T1DM and healthy groups, respectively $(\mathrm{p}=0.003)$. The mean values of ACD were $3.69 \pm 0.31 \mathrm{~mm}$ and $3.83 \pm 0.27 \mathrm{~mm}$ in T1DM and healthy groups, respectively $(p=0.02)$. The mean values of PD were $4.29 \pm 1.2 \mathrm{~mm}$ and $5.17 \pm 1.36 \mathrm{~mm}$ in T1DM and healthy groups, respectively $(p=0.001)$. There was no statistically significant difference between groups in terms of ECD, CV, ICA, K1, K2, and HVID ( $p>0.05$ ).
\end{abstract}

Conclusion. Type 1 diabetes mellitus children have thicker corneas, shallower anterior chamber depth, and smaller pupillary diameter than healthy subjects.

Key words: anterior segment parameters, corneal topography, endothelial morphology, type 1 diabetes mellitus.

Type 1 diabetes mellitus (T1DM) is the most common metabolic disease in childhood. It is a chronic illness characterized by high blood glucose levels due to an inability to produce insulin. This disease affects 500,000 patients globally. ${ }^{1}$ The prevalence of T1DM in Turkey is $75 / 100000 .^{2} \mathrm{~T} 1 \mathrm{DM}$ is a systemic disease that can affect all organ systems. ${ }^{3-5}$ Diabetic retinopathy is the most common complication of T1DM. ${ }^{6}$ But it can also affect the anterior segment of the patients. ${ }^{7-13}$ Some studies have demonstrated

$凶$ Alper Halil Bayat

alperhalil76@hotmail.com

Received 18th March 2019, revised 28th October 2019, accepted 30th October 2019. that patients with T1DM had greater central corneal thickness (CCT) than non-diabetic subjects. ${ }^{11}$ Anterior chamber depth (ACD) was found to be shallower in DM patients due to thickening of lens because of hyperglycemia.-9 T1DM can also cause sympathetic autonomic neuropathy. T1DM can affect response and the duration time of the sympathomimetics. ${ }^{13}$ Because of these effects on sympathomimetics, pupillary diameter was found to be smaller in diabetic patients. ${ }^{13}$ The main outcomes of these cited studies have addressed crystalline lens and anterior chamber depth; however, morphologic and functional changes in cornea and anterior segment parameters have been studied less frequently in diabetic children. This 
study aimed to compare corneal endothelial morphology and anterior segment parameters in diabetic children and healthy controls by corneal topography and noncontact specular microscopy.

\section{Material and Methods}

The eyes of 56 patients with T1DM and the eyes of 50 age-sex matched healthy subjects were examined in this study. T1DM patients were referred to us through pediatric endocrinology clinics between June 2018 and July 2018. Ethical Committee approval for the study was obtained (protocol number 09.2018.120). Written informed consent was obtained from all the parents of the children.

All participants underwent a total ophthalmic examination. Best-corrected visual acuity, slit-lamp examination, intraocular pressure measurements with pneumotonometer, fundus examination, and refraction measurements with autokeratorefractometer were performed. Refraction measurements and fundus examination were performed after cycloplegia. The duration of DM, age, gender, and Hemoglobin A1c (HbA1c) levels were recorded for diabetic children. Patients with any of the following criteria were excluded from the study: $>18$ years old, contact lens users, previous ocular trauma, history of ocular surgery, ocular inflammation, refractive errors $>$ \pm 1.00 (spherical or cylindrical), corneal disease, and cataracts. Measurements of endothelial morphology, such as endothelial cell density (ECD) and coefficient of variation (CV) of cell area were examined by noncontact specular microscopy using an EM-3000 Specular Microscope (CBD/Tomey, Phoenix, AZ, USA). Anterior segment parameters, such as CCT, $A C D$, iridocorneal angle (ICA), sim $\mathrm{K} 1$ and $\mathrm{K} 2$, pupillary diameter (PD), and horizontal visible iris diameter (HVID) were examined by Sirius Scheimpflug topography (Costruzione Strumenti Oftalmici, Florence, Italy). The Siruis topography examination was performed 2 days after cycloplegia by the same person. Because of the correlation between right and left eye, only the right eyes of the participants were analyzed. $\mathrm{HbA} 1 \mathrm{c}$ levels were obtained from pediatric clinic on the same day.

Statistical analyses were performed using the SPSS software version 21. Descriptive analyses were presented using means and standard deviations for normally distributed variables. An assessment of normality was done using the Kolmogorov-Smirnov test. The independent t, Man-Whitney U, Chi-squared, and Pearson correlation tests were used for analyses. A p-value of less than 0.05 was considered to show a statistically significant result.

\section{Results}

In the T1DM group, the female/male ratio was $32 / 24$, while it was $28 / 22$ in the healthy group $(p=0.454)$. The mean age was $14.3 \pm 3.2$ years in the T1DM group and $13.2 \pm 3.7$ years in the healthy group $(\mathrm{p}=0.140)$. The mean duration of diabetes mellitus was $4.5 \pm 3.5$ years. The mean $\mathrm{HbA} 1 \mathrm{c}$ was $9.5 \pm 1.9 \%$ (minimum $6 \%$, maximum $14 \%)$.

In terms of corneal endothelial morphology, the mean ECD values were $2975 \pm 248$ cells/ $\mathrm{mm}^{2}$ and $3012 \pm 257$ cells $/ \mathrm{mm}^{2}$ in the T1DM and healthy groups, respectively. There was no statistically significant difference between groups $(p=0.458)$. The mean $C V$ values were $0.36 \pm 0.06$ and $0.35 \pm 0.08$ in the T1DM and healthy groups, respectively. Regarding CV, there was no statistically significant difference $(p=0.608)$. Regarding topographic anterior segment parameters, the mean values of CCT were $556 \pm 30 \mu \mathrm{m}$ and $536 \pm 36 \mu \mathrm{m}$ in T1DM and healthy groups, respectively $(p=0.003)$ (Fig. 1). The mean values of ACD were $3.69 \pm 0.31 \mathrm{~mm}$ and $3.83 \pm 0.27 \mathrm{~mm}$ in T1DM and healthy groups, respectively $(p=0.02)$ (Fig. 2$)$. The mean values of ICA were $44.1 \pm 6.6$ and $45.5 \pm 7.3$ in T1DM and healthy groups, respectively $(p=0.297)$. The mean values of HVID were $12.15 \pm 0.53 \mathrm{~mm}$ and $12.14 \pm 0.44 \mathrm{~mm}$ in the T1DM and healthy groups, respectively $(p=0.914)$. In the T1DM 


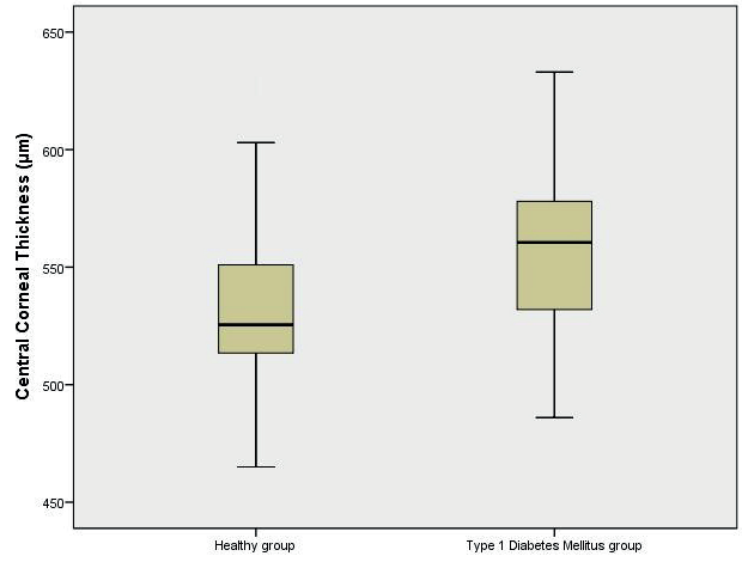

Fig. 1. Central corneal thickness values in groups.

group, the mean values of $\mathrm{K} 1$ and $\mathrm{K} 2$ were 42.75 $\pm 1.41 \mathrm{~mm} 42.37 \pm 1.5 \mathrm{~mm}$, respectively, and these values were $43.69 \pm 1.64 \mathrm{~mm}$ and $44.03 \pm$ $1.59 \mathrm{~mm}$ in the healthy group $(\mathrm{p}=0.191$ and $\mathrm{p}=$ 0.634 , respectively). The mean PD values were $4.29 \pm 1.2 \mathrm{~mm}$ and $5.17 \pm 1.36 \mathrm{~mm}$ in the T1DM and healthy groups, respectively $(p=0.001)$ (Fig. 3).

A significant positive correlation was detected when comparing the duration of diabetes and CCT $(r=0.277$ and $p=0.038)$. This correlation is presented in Figure 4. No statistically significant correlations were found between $\mathrm{HbA} 1 \mathrm{c}$ levels and PD, CCT, and ACD. No statistically significant correlations were found between the duration of DM, PD, and ACD. In T1DM groups, females had higher CVs than males

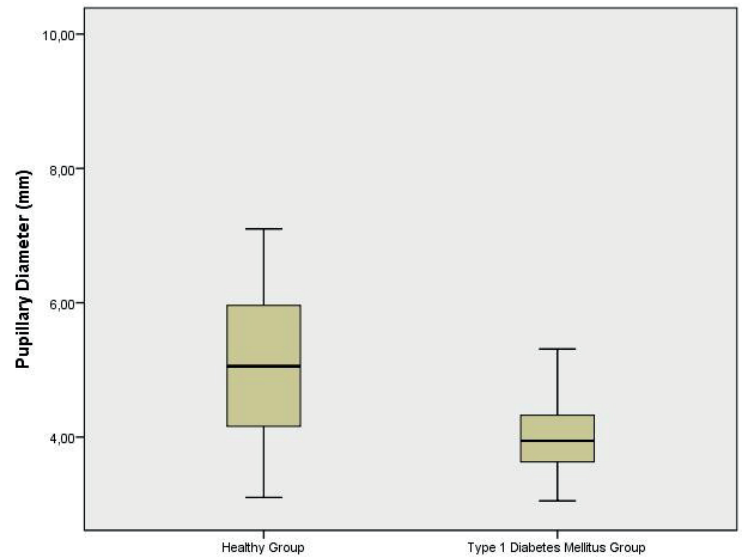

Fig. 3. Pupillary diameter in groups.

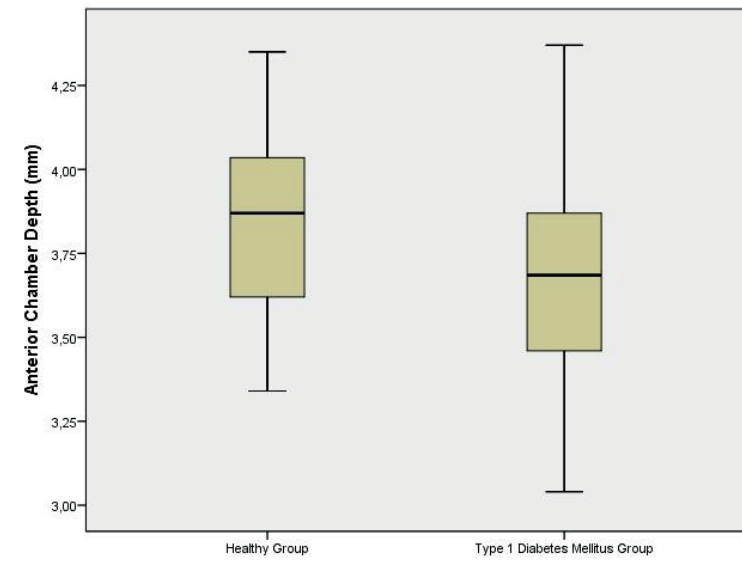

Fig. 2. Anterior chamber depth in groups.

(mean CV in females, $0.38 \pm 0.06$; mean $\mathrm{CV}$ in males, $0.32 \pm 0.04 ; \mathrm{p}<0.001)$.

\section{Discussion}

The Diabetic Control and Complications Trial (DCCT) has reported a lower risk for microvascular complications of T1DM. ${ }^{14}$ Beside microvascular complications, T1DM can also affect anterior segment parameters. Multiple studies have reported that T1DM affects the lens. ${ }^{1,715}$ In this study, we report that T1DM also affects corneal and anterior segment parameters.

Anbar et $\mathrm{al}^{16}$. found that $\mathrm{ECD}$ and $\mathrm{CV}$ values were lower in T1DM patients than the healthy controls, but they did not find any correlation

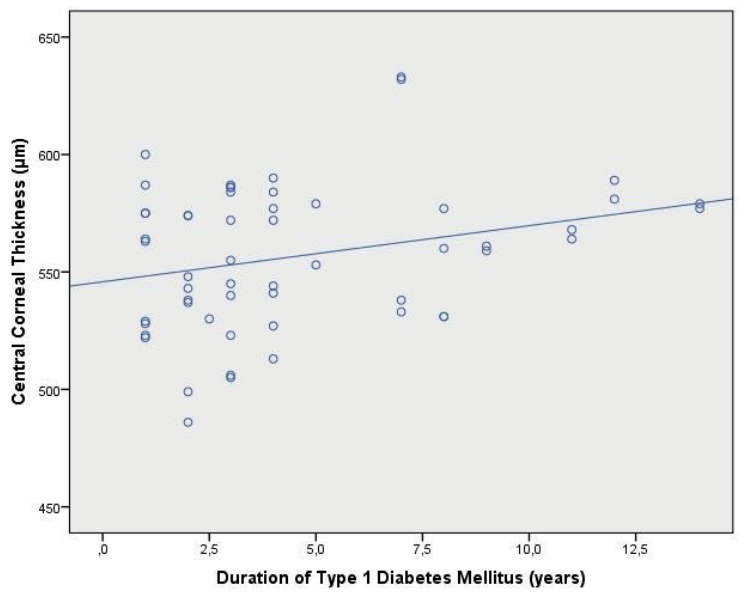

Fig. 4. Correlation between CCT and duration of type $1 \mathrm{DM}$. 
between ECD with the following variables: the age of the patients, gender, $\mathrm{HbA} 1 \mathrm{C}$ level, Body mass index and hemoglobin level. They only found a correlation with duration of T1DM and ECD. The duration of T1DM was also identified as a risk factor for changes in the polymegathism and pleomorphism in their study. These authors have established an increase in polymegathism and decrease in pleomorphism in T1DM children. ${ }^{16}$ Unlike Anbar et al. ${ }^{16}$ we found no difference in terms of endothelial parameters.

According to this study, there was no difference in endothelial parameters when comparing the T1DM and healthy groups. The same results were obtained by Larsson et al. ${ }^{17}$ Their study included 49 patients with T1DM and 60 patients with T2DM, and their outcomes concluded that type 1 and type 2 diabetes patients did not differ from their controls in ECD. Also, Larsson et al. ${ }^{17}$ noticed a significant decrease in endothelial cell hexagonality and abnormalities in endothelial cell morphologic characteristics in T1DM patients when compared to their controls.

As in this study, Ozdamar et al. ${ }^{18}$ also found that CCT values were higher in diabetic patients than the healthy group. These authors compared one hundred diabetic patients with one hundredforty-five control subjects. In diabetic patients, the mean CCT value was $564 \pm 30 \mu \mathrm{m}$, compared to $558 \pm 35 \mu \mathrm{m}$ in the healthy controls. Although they compared adult diabetes patients, the results were the same as the current study. In another study with diabetic children, Urban et al. ${ }^{19}$ compared 123 eyes of T1DM children with 124 eyes of a control group. These authors reported that T1DM children had a CCT value of $550 \pm 30 \mu \mathrm{m}$, while control subjects had a value of $530 \pm 33 \mu \mathrm{m}$. Tiutiuca et al. ${ }^{20}$ found that T1DM children had a CCT value of $541 \pm 30$ in their right eye, and control subjects had a CCT value of $528 \pm 33$. These studies supported our results. Additionally, there is a positive correlation between T1DM duration and CCT in our study. Busted et al. ${ }^{21}$ also reported that thicker CCT and lower ECD were correlated with duration of DM. Lee et al. ${ }^{22}$ found a correlation between duration of DM and thicker CCT; these authors also reported that there was no correlation between duration of DM and ECD. Although there is a pathogenic hypothesis for this, such as corneal endothelial pump dysfunction and swelling cornea, any strong associations have not been established. The reasons for these contracting findings must be investigated in pathological studies.

Wiemer et al. ${ }^{7}$ investigated the effects of type 1 and type $2 \mathrm{DM}$ on the cornea with scheimplug topography. Subjects were investigated for asphericity of anterior and posterior corneal surfaces and corneal power. The authors did not find a significant difference between diabetic subjects and healthy subjects. Uzel et al. ${ }^{15}$ also did not detect any difference in $\mathrm{K} 1$ or $\mathrm{K} 2$ when comparing the T1DM and healthy groups. In this current study, we also did not find any statistically significant difference in $\mathrm{K} 1$ and $\mathrm{K} 2$.

Impaired glucose metabolism can cause swelling of the lens. Decreased anterior chamber may occur due to metabolic swelling of the lens. ${ }^{15}$ Multiple studies have investigated and found shallower anterior chambers in T1DM patients compared to a healthy group. ${ }^{10,15}$ As in those studies, our T1DM patients had significantly shallower ACD than our healthy group. However, there was no correlation between T1DM duration and ACD, as also reported by Uzel et al..$^{15}$ These authors also identify a thicker lens as the reason for the decreased ACD in T1DM patients.

T1DM can also cause sympathetic autonomic neuropathy. Thus, T1DMcan affect response and the duration time of the sympathomimetics. ${ }^{13,15}$ Studies have reported smaller PD in T1DM patients relative to healthy groups (e.g., like Lei et $\mathrm{al}^{13}{ }^{13}$ ). These authors also report that T1DM patients with diabetic retinopathy had a smaller PD. It In the current study we could not compare the effect of the diabetic retinopathy, because none of our patients had developed it. Uzel et al. ${ }^{15}$ reported that this smaller PD also negatively correlated with HBA1c levels, indicating a relation between pupil size and poor diabetes control. ${ }^{15}$ In this study, there was 
no correlation between HBA1c, PD, CCT, and ACD. We also could not detect any correlation between T1DM duration and PD.

In the T1DM group, females had a higher CV than males, but the other parameters showed no sex differences. The study by Saw et al. ${ }^{10}$ included 1453 healthy children between 7 and 9 years old. Males were found to have a longer axial length, flatter corneal curvature radius, deeper $A C D$, and vitreous chamber than the females. They also reported a longer axial length and a deeper vitreous chamber in taller children. ${ }^{10}$ Therefore, different outcomes of gender might also be related to body height differences.

Consequently, T1DM was found to affect anterior segment parameters. Diabetic children have thicker cornea, lower ACD, and smaller PD. Although the duration of DM affects CCT, it does not affect PD or ACD. We recommend that these factors should be taken into consideration during the examination of patients with T1DM.

\section{REFERENCES}

1. Patterson C, Guariguata L, Dahlquist G, Soltész G, Ogle G, Silink M. Diabetes in the young - a global view and worldwide estimates of numbers of children with type 1 diabetes. Diabetes Res Clin Pract 2014; 103: 161-175.

2. Yeşilkaya E, Cinaz P, Andıran N, et al. First report on the nationwide incidence and prevalence of Type 1 diabetes among children in Turkey. Diabet Med 2017; 34: 405-410.

3. El-Ziny MAEM, Salem NAB, El-Hawary AK, Chalaby NB, Elsharkawy AAE. Epidemiology of childhood type 1 diabetes mellitus in Nile Delta, northern Egypt-a retrospective study. J Clin Res in Pediatr Endocrinol 2014; 6: 9-15.

4. Misra R, Fitch C, Roberts D, Wright D. Communitybased diabetes screening and risk assessment in rural west Virginia. J Diabetes Res 2016; 2016: 2456518.

5. Imkampe AK, Gulliford MC. Trends in Type 1 diabetes incidence in the UK in 0- to 14-year-olds and in 15- to 34-year olds,1991-2008. Diabet Med 2011; 28: 811-814.
6. Geloneck MM, Forbes BJ, Shaffer CJ, Ying GS, Binenbaum G. Ocular complications in children with diabetes mellitus. Ophthalmology 2015; 122: 2457-2464.

7. Wiemer NG, Dubbelman M, Kostense PJ, Ringens PJ, Polak BC. The influence of diabetes mellitus type 1 and 2 on the thickness, shape, and equivalent refractive index of the human crystalline lens. Ophthalmology 2008; 115: 1679-1686.

8. Wiemer NG, Dubbelman M, Hermans EA, Ringens PJ, Polak BC. Changes in the internal structure of the human crystalline lens with diabetes mellitus type 1 and type 2. Ophthalmology 2008; 115: 2017-2023.

9. Raitelaitiene R, Paunksnis A, Ivanov L, Kurapkiene S. Ultrasonic and biochemical evaluation of human diabetic lens. Medicina (Kaunas) 2005; 41: 641-648.

10. Saw SM, Wong TY, Ting S, Foong AW, Foster PJ. The relationship between anterior chamber depth and the presence of diabetes in the Tanjong Pagar Survey. Am J Ophthalmol 2007; 144: 325-326.

11. Wiemer NG, Dubbelman M, Kostense PJ, Ringens PJ, Polak BC. The influence of chronic diabetes mellitus on the thickness and the shape of the anterior and posterior surface of the cornea. Cornea 2007; 26: 1165-1170.

12. Pittasch D, Lobmann R, Behrens-Baumann W, Lehnert H. Pupil signs of sympathetic autonomic neuropathy in patients with type 1 diabetes. Diabetes Care 2002; 25: 1545-1550.

13. Lei HL, Yang KJ, Sun CC, et al. Obtained mydriasis in long-term type 2 diabetic patients. J Ocul Pharmacol Ther 2011; 27: 599-602.

14. Lachin JM, Genuth S, Cleary P, Davis MD, Nathan DM; Diabetes Control and Complications Trial/ Epidemiology of Diabetes Interventions and Complications Research Group. Retinopathy and nephropathy in patients with type 1 diabetes four years after trial of intensive therapy. $\mathrm{N}$ Engl J Med 2000; 432: 381-389.

15. Uzel MM, Elgin U, Sen E, Keskin M, Sağsak E, Aycan Z. Comparison of anterior segment parameters in juvenile diabetes mellitus and healthy eyes. Eur J Ophthalmol 2016; 26: 618-622.

16. Anbar M, Ammar H, Mahmoud RA. Corneal endothelial morphology in children with type 1 diabetes. J Diabetes Res 2016; 2016: 7319047.

17. Larsson LI, Bourne WM, Pach JM, Brubaker RF. Structure and function of the corneal endothelium in diabetes mellitus type I and type II. Arch Ophthalmol 1996; 114: 9-14. 
18. Ozdamar Y, Cankaya B, Ozalp S, Acaroglu G, Karakaya J, Ozkan SS. Is there a correlation between diabetes mellitus and central corneal thickness? J Glaucoma 2010; 19: 613-616.

19. Urban B, Raczynska D, Bakunowicz-Lazarczyk A, Raczynska K, Krętowska M. Evaluation of corneal endothelium in children and adolescents with type 1 diabetes mellitus. Mediators Inflamm 2013; 2013: 913754 .

20. Tiutiuca C. Assessment of central corneal thickness in children with diabetus mellitus type I. Oftalmologia 2013; 57: 26-32.
21. Busted N, Olsen T, Schmitz O. Clinical observations on the corneal thickness and the corneal endothelium in diabetes mellitus. Br J Ophthalmol 1981; 65: 687690.

22. Lee JS, Oum BS, Choi HY, Lee JE, Cho BM. Differences in corneal thickness and corneal endothelium related to duration in diabetes. Eye (Lond) 2006; 20: 315-318. 